\title{
Thermal Effect on the Distribution of Regular Sterane and Geological Significance
}

\author{
Yunfei Yang1,2, Min Zhang1,2*, Julin Chen"1,2, Xiaohui Chen ${ }^{1,2}$ \\ ${ }^{1}$ Key Laboratory of Exploration Technology for Oil and Gas Research (Yangtze University), Ministry of Education, Wuhan, China \\ ${ }^{2}$ College of Resources and Environment, Yangtze University, Wuhan, China \\ Email: *zmjpu@163.com
}

How to cite this paper: Yang, Y.F., Zhang, M., Chen, J.L. and Chen, X.H. (2017) Thermal Effect on the Distribution of Regular Sterane and Geological Significance. Open Journal of Yangtze Gas and Oil, 2, 249-259.

https://doi.org/10.4236/ojogas.2017.24020

Received: July 21, 2017

Accepted: October 27, 2017

Published: October 30, 2017

Copyright $\odot 2017$ by authors and Scientific Research Publishing Inc. This work is licensed under the Creative Commons Attribution International License (CC BY 4.0).

http://creativecommons.org/licenses/by/4.0/

c)

\begin{abstract}
In order to study thermal effect on distribution characteristics of regular sterane in humic coals, a suit of 25 coals derived from Kuqa Depression in Tarim Basin and Ordos Basin are studied to investigate the distribution of regular sterane in different maturity, which mainly discusses the thermal effect. The results show that the $\mathrm{C}_{27} \alpha \alpha \alpha / \mathrm{C}_{29} \alpha \alpha \alpha$ regular sterane ratio has a linear relationship with $R_{\mathrm{o}}\left(t_{\max }\right)$ and aromatic hydrocarbon maturity parameters in the coals from mature to high-mature stage. It suggests that the distribution of the $\mathrm{C}_{27}, \mathrm{C}_{29}$ regular steranes will fail to reflect original source input in high evolutionary stage. On the basis of thermal simulation experiment results, it further proves that the distribution patterns result from the demethylation effect of $\mathrm{C}_{29}$ sterane in the mature to high mature evolution stage and the $\mathrm{C}_{27} \alpha \alpha \alpha / \mathrm{C}_{29} \alpha \alpha \alpha$ regular sterane increases with increasing maturity. The breakage of $\mathrm{C}-\mathrm{C}$ key in branched chain from $\mathrm{C}_{27}, \mathrm{C}_{29}$ regular steranes to make $\mathrm{C}_{27} \alpha \alpha \alpha / \mathrm{C}_{29} \alpha \alpha \alpha$ regular sterane ratio invariance at high and over mature stage. Therefore, the ratio can be used to distinguish the maturity in high and over mature stage.
\end{abstract}

\section{Keywords}

Sterane, Maturity, Pyrolysis Experiment, Geochemistry Characteristic, Oil-Rock Correlation

\section{Introduction}

Sterane refers to the compounds which derive from the animals, plants and other organisms for complex sterol mixture of coal, hydrocarbon source rocks and crude oil species [1]. Because of its special structure containing rich geochemical information, it is often used to study oil source correlation, sedimentary environment, thermal evolution degree, the biodegradation and geological evolution history [2] [3] [4] [5] [6]. So far, these geochemical properties of sterane com- 
pounds had been researched by many domestic and foreign scholars. The research has shown that the carbon number distribution of regular sterane is mainly affected by organic matter input, indicating that regular sterane compound could act as powerful source parameters. $\mathrm{C}_{27}$ regular sterane indicates the source of aquatic algae, while $\mathrm{C}_{29}$ regular sterane suggests the source of higher plants. So the relative percentage content of $\mathrm{C}_{27}, \mathrm{C}_{28}$ and $\mathrm{C}_{29}$ regular sterane can be frequently used to judge source input and oil source correlation [1] [7] [8]. If the compound of $\mathrm{C}_{27}$ and $\mathrm{C}_{29}$ regular sterane appears on a double peak in the chromatograms, this can be speculated that the Organic matter is not only derived from continental deposits but also from Marine deposits [9].

In 1975, Alomon studied the influence of clay minerals for oil and gas formation mechanism using pyrolysis experiment [10]. Meanwhile, the relationship of sterane and thermal evolution was studied in the Paris Basin shale, and the maturity parameters of $\mathrm{C}_{29} 20 \mathrm{~S} /(20 \mathrm{~S}+20 \mathrm{R})$ and $\mathrm{C}_{29}-\beta \beta /(\alpha \alpha+\beta \beta)$ regular sterane were first put forward by Mackenzie in 1980 [11]. Because the $\mathrm{R}$ configuration on sterane C-20 was considered that it exists only in the precursor of living creatures' body. With the buried depth and thermal evolution degree increasing, the $\mathrm{R}$ configuration gradually converts a mixture of $\mathrm{R}$ and $\mathrm{S}$ configuration until to balance. After that, the phenomenon of the $\mathrm{C}_{29}$ regular sterane maturity parameter reversing was found in high maturity of hydrocarbon source rocks [12] [13]. In addition, immature hydrocarbon source rocks have done the pyrolysis experiments in the conditions of $320^{\circ} \mathrm{C}$ pyrolysis water using $72 \mathrm{~h}$. The distribution of regular steranes showed great changes under pyrolysis experiments, compared with immature hydrocarbon source rocks. The relative content of the $\mathrm{C}_{27}$ regular sterane was found an increase in pyrolysis experiments with the maturity increasing. That is to say, when reaching high and over matured stage, the relatively percentage of $\mathrm{C}_{27}, \mathrm{C}_{28}$ and $\mathrm{C}_{29}$ regular sterane can indicate homogenization. The result shows that the $\mathrm{C}_{27}, \mathrm{C}_{28}$ and $\mathrm{C}_{29}$ regular sterane are uneffective to determine source type [14] [15] [16].

Although the sterane compounds have been researched widely, the relationships between the regular sterane and the thermal evolution degree have rarely been studied in nature profile. Hence, the present paper comprises a detailed study of 25 coal samples from the Tarim Basin and Ordos Basin. Through the study of the pyrolysis analysis, total organic carbon (TOC) analysis, Biomarker compounds and vitrinite reflectance and whole rock maceral analysis, the aim of this research is to explore the thermal effect on the regular sterane in hydrocarbon source rocks. In addition, it is significant for oil-source correlation and the identification of primary hydrocarbon source rocks in high-over mature, which provides the theoretical foundation for the hydrocarbon generation mechanism in coal.

\section{Experimental and Samples}

\subsection{Samples}

A total of 25 coal samples were collected from the Ordos Basin and Tarim Basin. 
Ten coal samples are selected from $\mathrm{C}_{2} \mathrm{y}, \mathrm{C}_{2} \mathrm{j}, \mathrm{C}_{2} \mathrm{~b}, \mathrm{P}_{1} \mathrm{t}$ and $\mathrm{P}_{1} \mathrm{~s}$ of Carboniferous to Permian in Ordos Basin, which mainly develops alluvial fan, delta, marshes and tidal flat sedimentary environment [17] [18] [19] [20]. Another coal samples are from $\mathrm{T}_{3} \mathrm{~h}, \mathrm{~T}_{3} \mathrm{t}, \mathrm{J}_{1} \mathrm{y}, \mathrm{J}_{2} \mathrm{k}$ and $\mathrm{J}_{2} \mathrm{q}$ of Triassic to Jurassic, where sedimentary environment is fan delta system [19] [20]. Nineteen samples were selected for vitrinite reflectance and whole rock maceral analysis especially for this research. All coal samples were crushed into fine powder and analyzed for their contents of total organic carbon (TOC) and rock pyrolysis.

\subsection{Analytical Methods}

The measurement of reflectance and maceral were determined by Leica MPV-SP photomicroscope. Before the measurement, the samples were crushed to a maximum size of $1-\mathrm{mm}$. While at least 30 points were counted in every sample, then the type index $\left(T_{\mathrm{i}}\right)$ is used to calculate kerogen type indicators.

$$
\mathrm{TI}=(\text { sapropelic } \times 100+\text { exinite } \times 50+\text { vitrinite } \times(-75)+\text { inertinite } \times(-100)) / 100
$$

Fortotal organic carbon (TOC) and rock pyrolysis, all the coal samples need to be crush into fine powder and analyzed. However, before TOC determinations, all samples were removed by $\mathrm{HCl}$ treatment. The total carbon content was determined by LECO CS-2000 induction furnace. Pyrolysis was determined by Rock Eval VI made in China.

Bitumen "A" was extracted by the Soxhlet extraction for 3 days with a dichloromethane/methanol mixture $(93: 7 \mathrm{v} / \mathrm{v})$. Then, the extracted bitumens were fractionated into saturated, aromatic hydrocarbons, NSOs (nitrogen, sulfur and oxygen) and asphaltenes using open column chromatography filled silica gel and the alumina. The study mainly analyzes the saturate and aromatic hydrocarbons fraction. The model of gas chromatography-mass spectrometry is HP-GC 6980/5873 MSD. And the HP-6890 GC is equipped with a HP-5MS fused silica capillary column $(30 \mathrm{~m} \times 0.25 \mathrm{~mm} \times 0.125 \mu \mathrm{m})$. Helium is used as the carrier gas with a rate of $1.0 \mathrm{ml} / \mathrm{min}$. The injector temperature is $300^{\circ} \mathrm{C}$. The GC temperature is programmed to start at $50^{\circ} \mathrm{C}$ for $1 \mathrm{~min}$; the temperature will increase to $310^{\circ} \mathrm{C}$ at a rate of $3^{\circ} \mathrm{C} / \mathrm{min}$ with a final hold of $18 \mathrm{~min}$. The scanning range is 50 550 amu.

\section{Results and Discussion}

\subsection{Basic Geochemical Characteristics}

The results of rock pyrolysis and $R_{\mathrm{o}}$ determination showed that the maturity range of coal sample from the kuqa Depression in Tarim Basiniswide. $t_{\max }$ value range from $430^{\circ} \mathrm{C}$ to $529^{\circ} \mathrm{C}$. $R_{\mathrm{o}}$ ranges from $0.51 \%$ to $1.63 \%$ with an average value of $0.72 \%$. In contrast the maturity of the coal samples from the Ordos Basin is relatively high. The average of $R_{\mathrm{o}}$ is $0.99 \%$. In the whole rock maceral, $T_{\mathrm{i}}$ is an index to judge the type of parent material. The $T_{\mathrm{i}}$ index can be calculated using the relative percentage content of vitrinite, exinite, inertinite and so on. $T_{\mathrm{i}}$ values 
in the selected coal sample is $-68.48--37.88$, which reveals that all coal samples are III kerogen (Table 1).

Table 1. The basic geochemical data of source rocks in the study area.

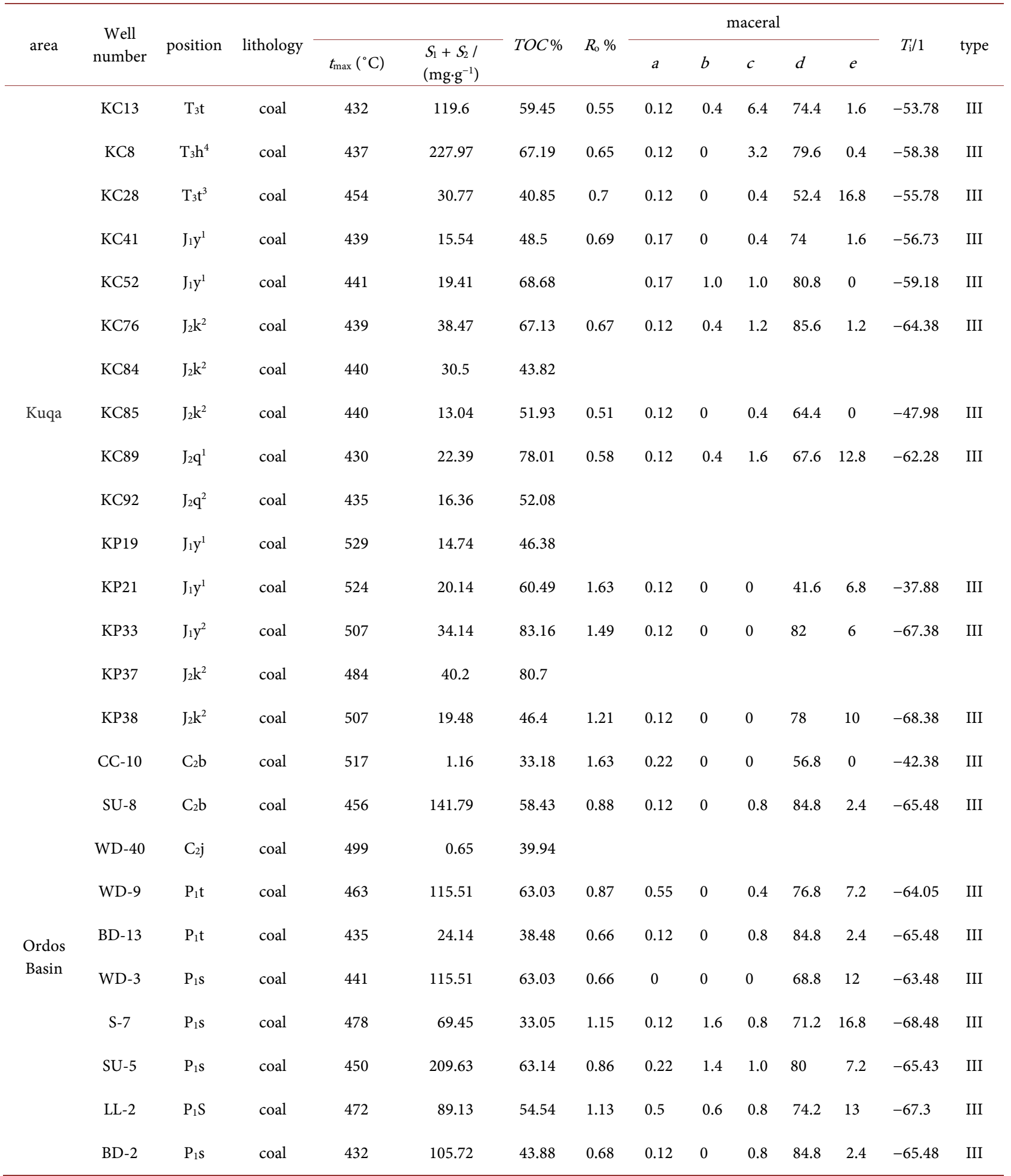

Note: $T_{\mathrm{i}}=(100 a+75 b+50 c+(-75) d+(-100) e) / 100, a, b, c, d$ and $e$ respectively represent nonfixiform organic matter, alginate, exinite, vitrinite and inertinite. 


\subsection{The Distribution of Sterane Compounds}

In this study, the complete distribution of sterane series compounds was detected in the coal sample from Kuqa Depression and Ordos Basin. When the $t_{\max }$ value is about $440^{\circ} \mathrm{C}\left(R_{0}=0.7 \%\right)$, the distribution of $\mathrm{C}_{27}$ and $\mathrm{C}_{29}$ regular sterane is consistent with the typical coal measures hydrocarbon source rocks with $\mathrm{C}_{29}$ regular sterane accounting for absolute advantage. It presents asymmetrical " $\mathrm{V}$ " type or the "L" type (Figure 1(a)). With the thermal evolution degree increasing, the typical coal sample of $\mathrm{C}_{29}$ regular sterane relative content advantage has disappeared. On the contrary, the relative content of $\mathrm{C}_{27}$ regular sterane has a tendency of increasing (Figure 1(b)). The distributions of different maturity sterane on the same section area in Ordos basin revealed that the relative content of $\mathrm{C}_{27}, \mathrm{C}_{29}$ regular sterane are consistent with typical coal measures hydrocarbon source rock under the condition of low maturity $\left(t_{\max }\right.$ value $441^{\circ} \mathrm{C}, R_{\mathrm{o}}$ values $0.66 \%)$. In other words, the $\mathrm{C}_{29}$ regular sterane has absolute predominance. However, with the increase of maturity, when the $t_{\max }$ value reaches $499^{\circ} \mathrm{C}, \mathrm{C}_{27}$ regular sterane predominates, which is similar to Figure $2(\mathrm{~b})$. This phenomenon is consistent with previous studies, when thermal evolution degree is higher; the $\mathrm{C}_{27}$ regular sterane relative content will gradually increase with the increasing maturation [21]. Although the samples from the same section, the distribution of $\mathrm{C}_{27}$ sterane and $\mathrm{C}_{29}$ sterane is different in different maturity. However, the distribution of $\mathrm{C}_{27}$ sterane and $\mathrm{C}_{29}$ steraneis consistency are in different parts of the section under the condition of similar maturity. Compared $\mathrm{C}_{27}$ sterane and $\mathrm{C}_{29}$ sterane, $\mathrm{C}_{28}$ sterane has no obvious change in the same profile under the condition of different maturity. That is to say, the distribution of sterane cannot be used to distinguish the hydrocarbon source rocks in the same area under the condition of different maturity.

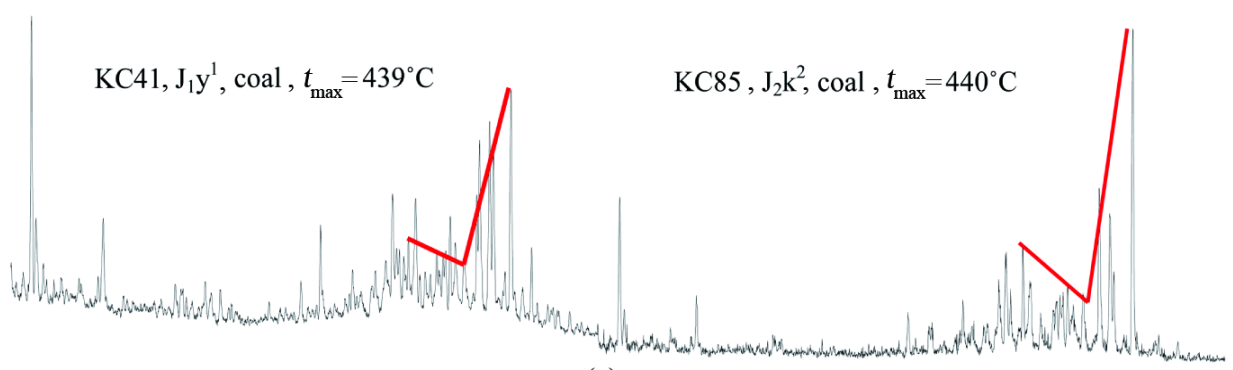

(a)

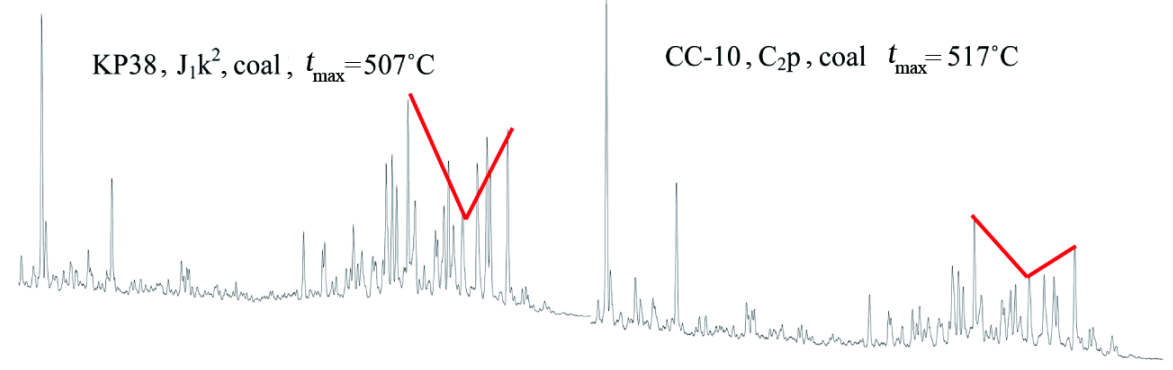

(b)

Figure 1. The distributions of sterane in different mature coal from Kuga sag and Ordos Basin. 


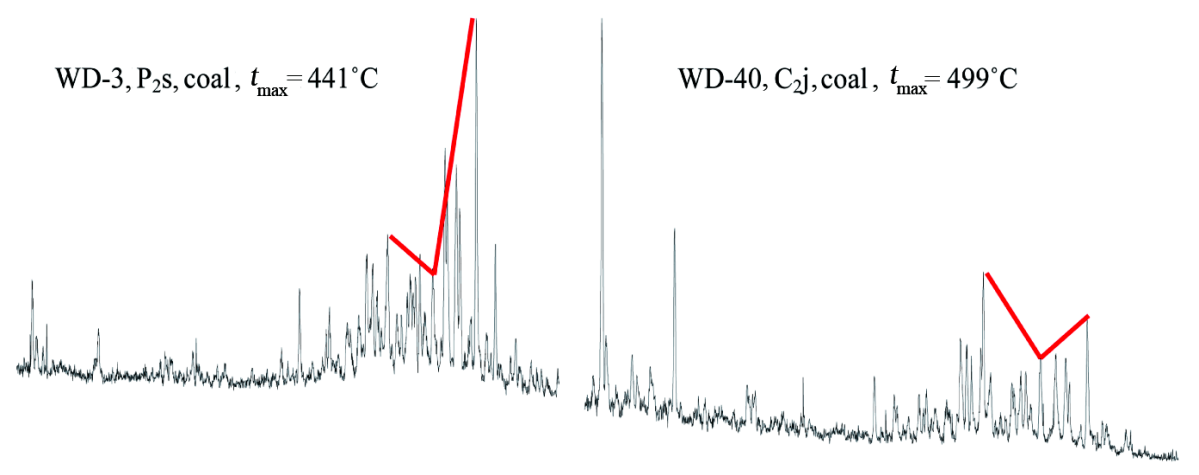

Figure 2. The distributions of sterane in different mature coal from the same profile Ordos Basin.

\subsection{The Relative Content Change of Sterane Compounds}

In general, aquatic organisms are rich in $\mathrm{C}_{27} \alpha \alpha \alpha 20 \mathrm{R}$ sterane, while terrigenous higher plants are rich in $\mathrm{C}_{29} \alpha \alpha \alpha 20 \mathrm{R}$ sterane. That view has been generally accepted [22]. The relationship between the relative content $\mathrm{C}_{27}, \mathrm{C}_{28}, \mathrm{C}_{29}$ regular sterane and the vitrinite reflectance $R_{0}(\%)$ in Kuqa Depression in Tarim Basin and Ordos Basin reveals that the thermal action has influence to the $\mathrm{C}_{27}, \mathrm{C}_{28}$ and $\mathrm{C}_{29}$ regular sterane. When the $R_{\mathrm{o}}(\%)$ value is less than $0.7 \%$, the coal samples are still accounts for absolute advantage for $\mathrm{C}_{29}$ regular sterane. With the higher evolution degree, the relative content of $\mathrm{C}_{29}$ regular sterane gradually diminishes, while the $\mathrm{C}_{27}$ regular sterane increases. This leads to "invert" phenomenon that the content of $\mathrm{C}_{27}$ regular sterane is greater than the content of $\mathrm{C}_{29}$ regular sterane with the $R_{\mathrm{o}}$ (\%) values increasing continually. In the stage of mature to high mature, the relative content of $\mathrm{C}_{28}$ regular sterane seems to be no obvious change. Thus, in the high and over mature evolutionary stages, when using the $\mathrm{C}_{27}, \mathrm{C}_{28}$ and $\mathrm{C}_{29}$ regular sterane to judge parent material types needs to be careful. Otherwise, the conclusions from the distribution of regular sterane may be inconsistent with the practical point in the natural profile.

\subsection{The Relationship between the Sterane Compound and the Maturity Parameter $R_{0}$ and $t_{\max }$}

Previous studies illustrated the change rule of the $\mathrm{C}_{27}, \mathrm{C}_{28}$ and $\mathrm{C}_{29}$ regulars terane compounds with the increasing maturity in simulation experiments. The change is quite outstanding especially in high or over maturity [14] [15] [16]. To further exploring the relationship between the sterane $\mathrm{C}_{27}, \mathrm{C}_{28}$ and $\mathrm{C}_{29}$ regular sterane and the thermal action, the relationship between $\mathrm{C}_{27} / \mathrm{C}_{29}$ regular sterane ratio and maturity parameters of $R_{\mathrm{o}}(\%)$ and $t_{\max }\left({ }^{\circ} \mathrm{C}\right)$ were discussed firstly (Figure 3). When $R_{\mathrm{o}}$ value is $0.7 \%-1.5 \%$, the $\mathrm{C}_{27} / \mathrm{C}_{29}$ regular sterane ratio has a good linear relationship with $R_{\mathrm{o}}$ in the Kuqa Depression and the Ordos Basin (Figure $4(\mathrm{a}))$. Mean while, the $\mathrm{C}_{27} / \mathrm{C}_{29}$ regular sterane ratio and $t_{\max }\left(<500^{\circ} \mathrm{C}\right)$ is a linear relationship, which is similar to the $R_{\mathrm{o}}(\%)$. That may be the thermal effect on the demethylation of $\mathrm{C}_{29}$ sterane obviously in the evolution stage of mature to high-mature [17] [23]. 


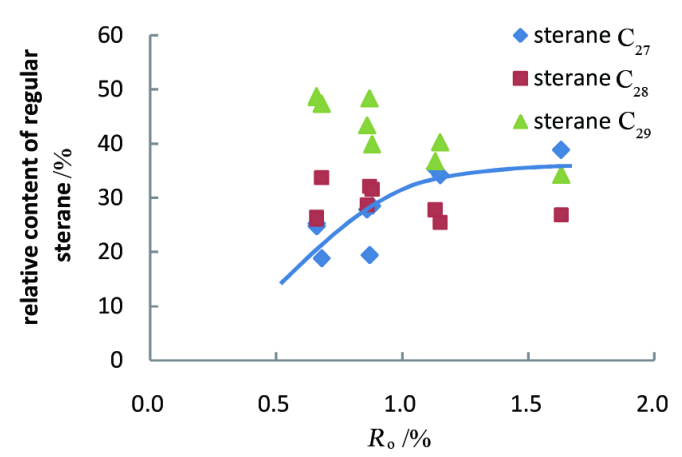

(a)

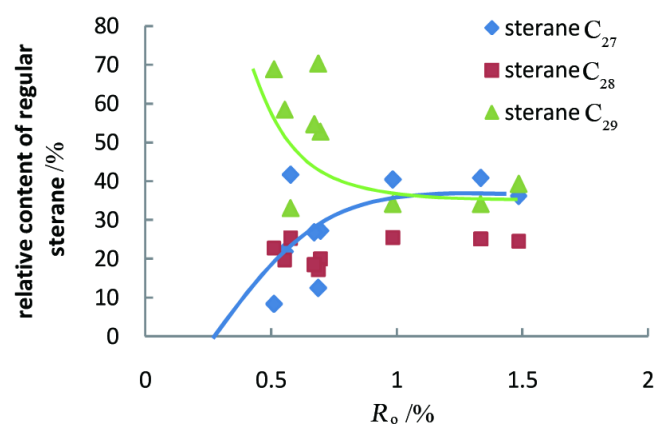

(b)

Figure 3. The plot relative content of regular sterane vs $R_{\mathrm{o}}(\%)$ from Kuga depression and Ordos Basin.

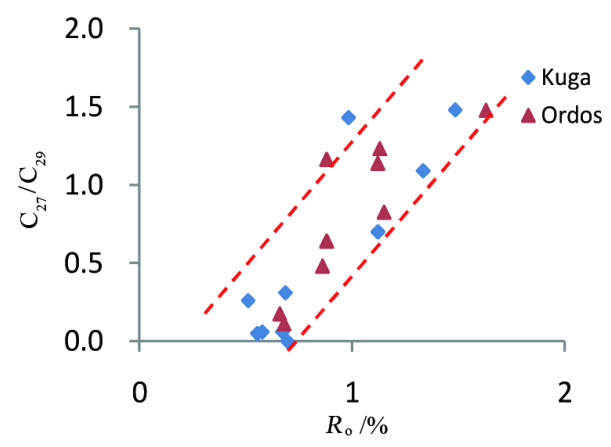

(a)

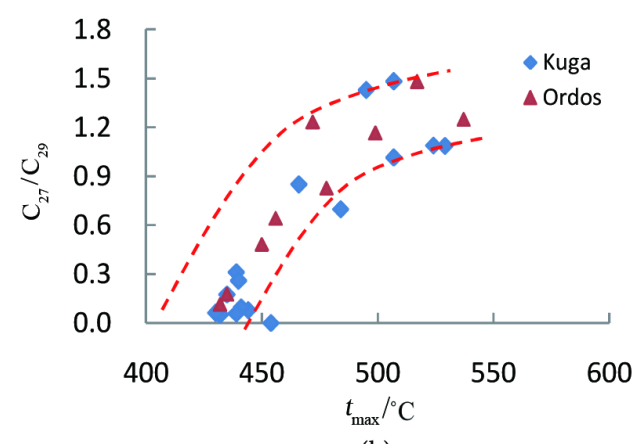

(b)

Figure 4. The plot sterane $\mathrm{C}_{27} / \mathrm{C}_{29}$ vs $R_{\mathrm{o}}$ and $t_{\max }$ of coal from Kuga sag and Ordos Basin.

\subsection{The Relationship between $\mathrm{C}_{27} / \mathrm{C}_{29}$ Ratio and Aromatics Maturity}

The coal samples are at low mature to over mature stage with $t_{\max }$ ranging from $432^{\circ} \mathrm{C}$ to $529^{\circ} \mathrm{C}$. The maturity parameters of saturated hydrocarbons have reached equilibrium value; so it cannot effectively represent the maturity of samples. However, compared with the maturity parameters of saturated hydrocarbon, the maturity parameters of aromatic hydrocarbon could judge the high maturity samples. In addition to the commonly used methyl phenanthrene index MPI [24] [25], Chakhmakhchev et al. put forward dimethyl-benzothiophene maturity parameters. The works of the relationship between $R_{0}$ and a dimethyl-benzothiophene ratio parameter have done a lot of. And the conversion formula of $R_{\mathrm{o}}$ and dimethyl-benzothiophene ratio has been put forward [26] [27]. The ratio of three methylnaphthalene $\mathrm{TMNr}=2,3-\mathrm{TMN} /(1,2,5-\mathrm{TMN}+$ 2,3,6-TMN) were put forward [28]. And when the ratio of TMNr is greater than 0.6 , it represents the high maturity [29]. In the aromatic compounds, many evaluation parameters can be used to evaluate the maturity. This present paper chose naphthalene, fluorene series compounds for research.

The $\mathrm{C}_{27} / \mathrm{C}_{29}$ regular sterane ratios and aromatic maturity parameters DMDBT and TMNr also have a good linear relationship. And the relationship is similar to $t_{\max }$ and $R_{\mathrm{o}}$ (Figure 5). That is to say the thermal of hydrocarbon source rocks 
has distinct effect on the relative concentration distribution of regular sterane $\mathrm{C}_{27}, \mathrm{C}_{28}$ and $\mathrm{C}_{29}$ regular sterane. So, in the same research area, the $\mathrm{C}_{27} / \mathrm{C}_{29}$ regular sterane ratio can be used to determine hydrocarbon source rock maturity, especially in mature-high and over mature stage of evolution.

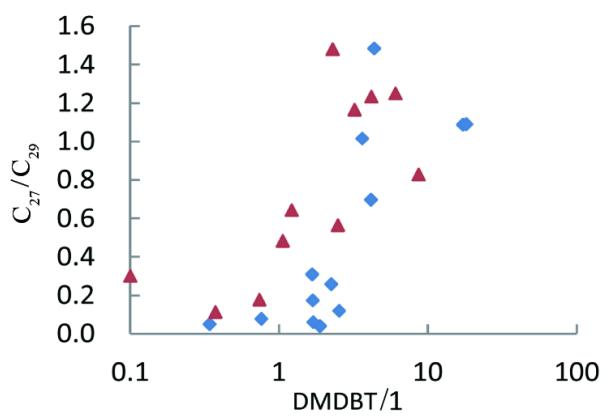

(a)

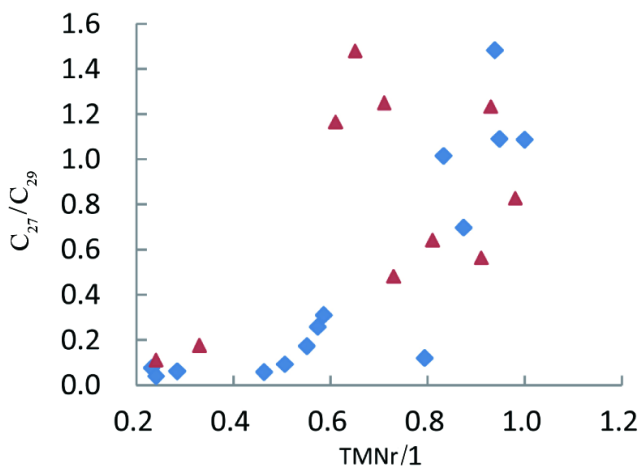

(b)

Figure 5. The plot $\mathrm{C}_{27} / \mathrm{C}_{29}$ sterane and aromatic maturity parameters from Kuga sag and Ordos Basin.

\subsection{The Change of Sterane in Thermal Simulation Experiment}

In order to demonstrate the thermal effect on sterane distribution rules, the thermal simulation test of a coal sample had been done. Six temperature points, $200^{\circ} \mathrm{C}, 250^{\circ} \mathrm{C}, 300^{\circ} \mathrm{C}, 350^{\circ} \mathrm{C}, 400^{\circ} \mathrm{C}, 450^{\circ} \mathrm{C}$, were chosen in the process of experiment. The results show that $\mathrm{C}_{27} / \mathrm{C}_{29}$ regular sterane ratio increases with the simulative temperature rising (Figure 6). This further elucidated that the influence of the distribution of $\mathrm{C}_{27}$ and $\mathrm{C}_{29}$ regular sterane in the sample is objective, especially, in the high-mature stage (thermal simulative temperature $>350^{\circ} \mathrm{C}$ ). The relationship of the absolute concentration of $\alpha \alpha \alpha \mathrm{C}_{27}, \mathrm{C}_{29}$ regular sterane and pyrolysis temperature are shown in Figure 6(b). The absolute concentration of $\mathrm{C}_{29}$ regular sterane decrease is faster than $\mathrm{C}_{27}$ sterane in low mature stage (thermal simulative temperature $<350^{\circ} \mathrm{C}$ ). But when the temperature is greater than $350^{\circ} \mathrm{C}$, the $\mathrm{C}_{27}$ regular sterane is increasing faster than $\mathrm{C}_{29}$ regular sterane. This phenomenon proves that the $\mathrm{C}_{27} / \mathrm{C}_{29}$ regular sterane ratio and the degree of thermal evolution have a certain correlation.

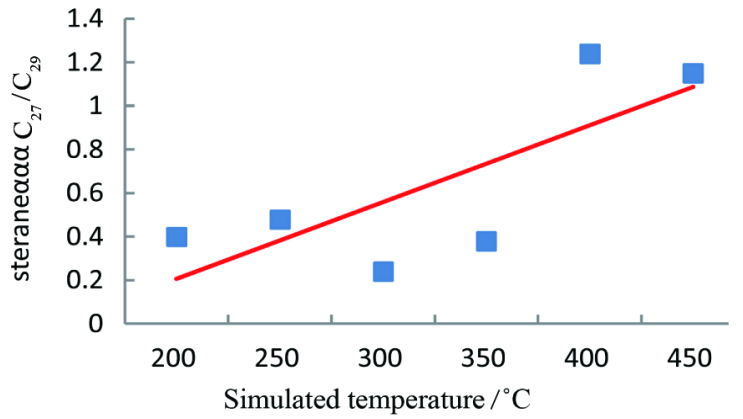

(a)

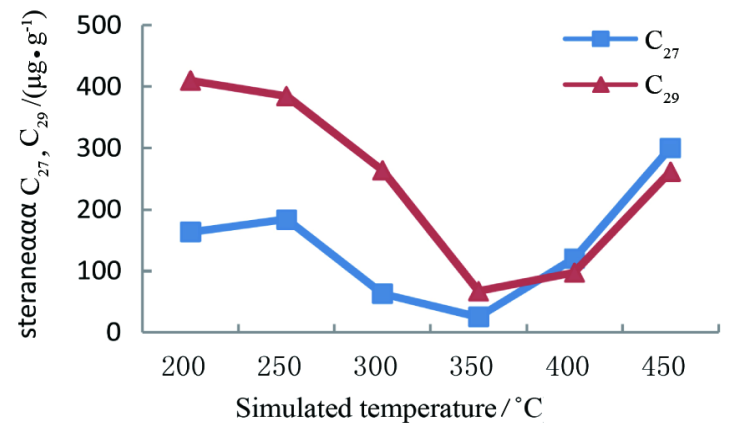

(b)

Figure 6. The variation of ratios $\mathrm{C}_{27} / \mathrm{C}_{29}$ sterane and $\mathrm{C}_{27}, \mathrm{C}_{29}$ sterane absolute concentration with simulated temperature. 
Structures determine properties in organic chemistry. It is because of the diversity of steranes compounds configuration change. Therefore, steranes compounds have high practical value in researching sources, thermal evolution and sedimentary environment of organic matter. In general, the longer chain of carbon alkane molecules is, the more will be easily broken. So the naphthene is steadier than side chain alkanes, and the more branched alkanes is prone to cracking reaction [30]. The $\mathrm{C}_{29}$ regular sterane adds an ethyl in C-24 place compared with the $\mathrm{C}_{27}$ regular sterane. Owing to hydrocarbons with different carbon number needing different chemical bond dissociation energy to fracture, it leads to the variation of $\mathrm{C}_{27} / \mathrm{C}_{29}$ regular sterane ratio with the increasing thermal maturity (Table 2).

Table 2. Bond dissociation energy related with the structure of sedimentary organic matter (Hou Dujie, et al. 2011) [31].

\begin{tabular}{cccccc}
\hline C-C key & $\mathrm{CH}_{3}-\mathrm{CH}_{3}$ & $\mathrm{C}_{2} \mathrm{H}_{5}-\mathrm{CH}_{3}$ & $\mathrm{C}_{3} \mathrm{H}_{7}-\mathrm{CH}_{3}$ & $\mathrm{C}_{4} \mathrm{H}_{9}-\mathrm{CH}_{3}$ & $\mathrm{C}_{3} \mathrm{H}_{7}-\mathrm{C}_{2} \mathrm{H}_{3}$ \\
\hline $\begin{array}{c}\text { Bond } \\
\text { dissociation } \\
\text { energy (kJ/mol) }\end{array}$ & 369 & 356 & 348 & 345 & 335 \\
\hline
\end{tabular}

\section{Conclusions}

1) The steranes, especially $\mathrm{C}_{27}, \mathrm{C}_{29}$ regular sterane compounds, are mainly controlled by source of parent material factor in evolution of hydrocarbon source rocks in the lower stage of development. The relative content of sterane compounds is very different in terrestrial higher plants and low aquatic algae parent material sources, so it can be served as an indicator of good source material. But on the high evolutionary stage, the relative content distribution of $\mathrm{C}_{27}$, $\mathrm{C}_{28}$ and $\mathrm{C}_{29}$ regular sterane tends to be "homogenization". In high evolution stage, therefore, it needs to be cautious to use the parameters of the relative content to determine parent material types and oil-source correlation.

2) In order to describe the relationship of the relative content of regular sterane and the thermal action, the pyrolysis experiment has been performed to show that the $\mathrm{C}_{27} / \mathrm{C}_{29}$ regular sterane ratio has a good of correlation with the maturity parameter like $R_{0}, t_{\max }$, aromatic compounds DMDBT and TMNr. The results are similar to natural geological section, which suggests that the distribution of regular sterane will be effected by the thermal evolution.

3) To understand the characteristics of thermal evolution, the formation mechanism of the $\mathrm{C}_{27} / \mathrm{C}_{29}$ regular sterane ratio with evolution degree changes is discussed by molecular structure stability. Due to the structural differences of $\mathrm{C}_{27}$ and $\mathrm{C}_{29}$ regular sterane, the demethylation effect is more apparent in $\mathrm{C}_{29}$ sterane than $\mathrm{C}_{27}$ sterane at mature to high mature evolution stage. It is the reason why the $\mathrm{C}_{27} / \mathrm{C}_{29}$ regular sterane ratio rise with thermal evolution degree increasing; however, when the thermal evolution levels continue to rise, the breakage of $\mathrm{C}-\mathrm{C}$ 
key in branched chain makes $\mathrm{C}_{27} / \mathrm{C}_{29}$ regular sterane ratio invariance at high and over mature stage. Therefore, the $\mathrm{C}_{27} / \mathrm{C}_{29}$ regular sterane ratio may be used to distinguish hydrocarbon source rock maturity in the similar sedimentary system at high and over mature stage.

\section{Acknowledgements}

This study was financially supported by the National Natural Science Foundation of China (Grant No. 41772124) and National Science and Technology Major Projects (2016ZX05007001-002).

\section{References}

[1] Philp, R.P. (1985) Fossil Fuel Biomarkers. Elsevier, New York, 1-294.

[2] Huang, D.F. and Lu, S.F. (1999) Current Situation and Prospect in Geochemistry of Oil from Coals. Earth Science Frontiers, 6, 183-194.

[3] Yang, B. and Li, J.X. (1989) Geochemical Characteristics of Coaliferous Oil and Gas of Yiqikelike Oil and Gasfield and the Prospect of the Kuqadepression. Petroleum Exploration and Development, No. 5, 1-7.

[4] Shang, H.Y., Tong, Y.Y. and Jian, N.H. (1982) Geochemical Characteristics of Steranes and Triterpanesin Erduosi Basin. Petroleum Exploration and Development, No.2, 18-28.

[5] Wang, Z.R., Zhang, Z.C. and Chen, X.Z. (1983) GC/MS Identification of Steranes, terpanes and Other Biomarkers. PetGeol Exp, No. 3, 230-238.

[6] Schwark, L. and Empt, P. (2006) Sterane Biomarkers as Indicators of Palaeozoic Algal Evolution and Extinction Events. Palaeogeography Palaeoclimatology Palaeoecology, 240, 225-236. https://doi.org/10.1016/j.palaeo.2006.03.050

[7] Peters, K.E. and Moldowan, J.M. (1993) Interpreting Molecular Fossils Inpetroleum and Ancient Sediments. Prentice Hall Inc., Upper Saddle River, 1-236.

[8] Huang, W.Y. and Meinschein, W.G. (1978) Sterols Are Ecological Indicators. Geoshimicaet Cosmochimica Acta, 43, 739-745. https://doi.org/10.1016/0016-7037(79)90257-6

[9] Zeng, G.T. and Xu, M.H. (1990) Petroleum Geochemistry. Petroleum Industry Press, Beijing, 1-287.

[10] Alomon, W.R. and John, W.D. (1975) Petroleum Forming Reaction: The Mechanism and Rate of Clay Catalyzed Fatty Acid Decarboxiolation. Advance of Organic Geochemistry, No. 7, 157-170.

[11] Chen, S., Wang, T. and Huang, Q. (1997) The Reversal of $\mathrm{C}_{29}$ Steraneand Its Geological Suggestion. Journal of Natural Gas Geoscience, No. 1, 28-30.

[12] Lewan, M.D., Bjoray, M. and Dolcater, D.L. (1986) Effects of Thermal Maturation on Steroid Hydrocarbons as Determined by Hydrous Pyrolysis of Phosphoria Retort Shale. Geochimica et Cosmochimica Acta, 50, 1977-1987.

[13] Sun, T. and Duan, Y. (2011) Geochmical Characteristics of Steranes of Coal Generated Hydrocarbon; A Case of High Temperature and Fined Simulated Experiment. Natural Gas Geoscience, 22, 1082-1087.

[14] Liu, Q., Liu, W.H. and Meng, Q. (2007) Geochmical Characteristics of Steranes in Saturated Hydrocabons from Coal and Exinite in Pyrolysis under Closed Systems. 
Natural Gas Geoscience, 18, 249-253.

[15] Wu, L. and Geng, A. (2016) Differences in the Thermal Evolution of Hopanes and Steranes in Free and Bound Fractions. Organic Geochemistry, 101, 38-48.

[16] Guo, X. (2010) Coal Accumulation and Target Optimization for Exploration of CBM in Permo-Carboniferous Ordos Basin. China University of Petroleum, 25-44.

[17] Cheng, X., Cheng, X. and Zhang, M. (2014) Origin of $7 \alpha(\mathrm{H})$-Rearranged Hopanes in Upper-Palaeozoic Coal-Bearing Source Rocks in Northeast Ordos Basin. Acta Sedimentologica Sinica, 32, 790-796.

[18] Liu, H., Qin, T. and Yang, Z. (2003) Sedimentary Facies of the Triassic-Jurassic Strata in the Tarim Basino, Xinjiang. Sedimentary Geology and Tethyan Geology.

[19] Zhang, J., Chen, J.P. and Zhang, C.M. (2002) Relationships between Bloanarker Composition and Maturity in Coal of Kuche Depression. Journal of Jianghan Petroleum Institute, 24, 27-29.

[20] Lu, S. and Zhang, M. (2008) Petroleum Geochemistry. Petroleum Industry Press, Beijing, 195-196.

[21] Cheng, K., Zhao, C. and Su, Y. (1997) A Study of Geological and Geochemical Conditions for Coal-Derived Oil and Gas Formation in Turpan-Hami Basin. Petroleum Explorationist, No. 2, 5-10.

[22] Radke, M., Welte, D.H. and Willsch, H. (1982) Geochemical Study on a Well in the Western Canada Basin: Relation of the Aromatic Distribution Pattern to Maturity of Organic Matter. Geochimica Et Cosmochimica Acta, 46, 1-10.

[23] Szczerba, M. and Rospondek, M.J. (2010) Controls on Distributions of Methylphenanthrenes in Sedimentary Rock Extracts: Critical Evaluation of Existing Geochemical Data from Molecular Modeling. Organic Geochemistry, 41, 1297-1311.

[24] Kvalhem, O., Hhrity, A.A. and Telnaes, N. (1987) Maturity Determination of Organic Matter in Coals using the Methylphenanthrene Distribution. Geochimica Cosmochimica Acta, 51, 1883-1888.

[25] Bao, J., Wang, T. and Zhou, Y. (1992) The Relationship between Methyl Phenanthrene Ratios and the Evolution of Organic Matter. Journal of Jianghan Petroleum Institute, 14, 8-13.

[26] Chakhmakhchev, A., Suzuki, M. and Takayama, K. (1997) Distribution of Alkylated Dibenzothiophenes in Petroleum as a Tool for Maturity Assessments. Organic Geochemistry, 26, 483-489.

[27] Luo, J., Cheng, K. and Fu, L. (2001) Alkylated Dibenzothiophene Index-A New Method to Assess Thermal Maturity of Source Rocks. Acta Pet Sinica, 22, 27-31.

[28] Van Aarssen, B.G.K., Bastow, T.P., Alexander, R. and Kagi, R.I. (1999) Distributions of Methylated Naphthalenes in Crude Oils: Indicators of Maturity, Biodegradation and Mixing. Organic Geochemistry, 30, 1213-1227.

[29] Jia, C., Wang, Y. and Gu, Y. (2009) Geochemical Characteristics of Aromatic Hydrocarbons of Crudeoils from Ordovician Reservoir in the Tahe Oilfield. Pet GeoIExp, 31, 384-388, 393.

[30] Tian, T., et al. (2002) Chemistry Technology. Chemical Industry Press, Beijing, 103-106.

[31] Hou, D. and Feng, Z. (2011) Petroleum Geochemistry. Petroleum Industry Press, Beijing, 18-19. 